\title{
História, política e educação a partir dos escritos de Walter Benjamin
}

Anita Helena Schlesener ${ }^{1}$

\begin{abstract}
Resumo: O objetivo desse trabalho é retomar escritos de Walter Benjamin a fim de articular história, política e educação e salientar a importância da educação no contexto da luta de classes. A educação se apresenta como modo de vida construído a partir das formas modernas de relação social e de vivência urbana que geraram, ao longo de um processo de séculos, a formação de uma nova sensibilidade e de um modo de pensar no qual se alojou o mito. Um projeto educativo para as classes trabalhadoras implica explicitar os mitos e elaborar uma história materialista da cultura, como parte de sua formação política. A dimensão política desta nova história (e nova educação) está no convite implícito aos oprimidos a redimir, no contexto de agora, o sofrimento e a opressão dos oprimidos do passado. Para tanto, a classe trabalhadora precisa tomar em suas mãos o processo educativo de seus filhos, no projeto de uma nova escola.
\end{abstract}

Palavras-chave: História, política, educação, Walter Benjamin.

\section{History, politics and education from Walter Benjamin's writings.}

\begin{abstract}
This text aims to retake Walter Benjamin's writings in order to articulate history, politics and education and to emphasize the importance of education in the context of the class struggle. Education presents itself as a way of life built from the modern forms of social relation and urban experience that generated, over a process of centuries, the formation of a new sensibility and a way of thinking in which myth was lodged. An educational project for the working classes implies making myths explicit and elaborating a materialistic history of culture as part of their political formation. The political dimension of this new history (and new education) lies in the implicit invitation of the oppressed to redeem, in the context of contemporaneity, the suffering and oppression of the oppressed of the past. To this end, the working class needs to take the educational process of their children into their hands, in a new school project.
\end{abstract}

Keywords: History; Politics; Education; Walter Benjamin.

${ }^{1}$ Doutora em História pela UFPR, Professora no Mestrado-Doutorado em Educação da UTP. E-mail: anitahelena1917@gmail.com 


\section{Introdução:}

Poder-se-ia dizer que é tanto mais subjugante um olhar quanto mais profunda é a ausência de quem olha (BENJAMIN, 1991, p. 67).

Iniciamos acentuando a característica particular do pensamento de Walter Benjamin a partir de sua formação clássica e do modo como entrecruzou posições teóricas opostas e mesmo contrárias, que vão do romantismo alemão, a Nietzsche e Freud, passando pelo anarquismo nas vertentes de Blanqui e Sorel e chegando ao marxismo pela via de Lukács (História e consciência de classe) e Karl Korsch (Karl Marx), formação que lhe deu condições de um pensamento crítico ferino e inovador (denominado pelo próprio autor em Passagens, de fissão nuclear). Um autor cuja peculiaridade se encontra nos escritos em fragmentos que trazem implícita uma teoria da modernidade, na constatação das profundas transformações ocorridas a partir do desenvolvimento da técnica e do seu aproveitamento no processo produtivo na economia capitalista.

A característica peculiar de sua filosofia consistia em articular as diversas tendências do pensamento moderno para mostrar novos significados possíveis; como acentua Adorno (1986, p. 188), "sob o olhar de suas palavras, onde quer que ele caísse, tudo se metamorfoseava como se tivesse se tornado radioativo". Benjamin pretendia "compreender o essencial ali onde ele não se deixa destilar numa operação automática": nas dobras e nos detalhes que escapam a toda sistematização. Neste contexto, “à sua planejada marginalidade, corresponde a sua suave irresistibilidade” (ADORNO, 1986, p. 189).

Suas densas metáforas possuem uma força crítica inusitada contra o historicismo na sua linearidade e progressividade, interrogando a história quantitativa e pontual, que se pretende universal, para desvelar o tempo subterrâneo, suprimido ou soterrado pela história dos vencedores.

O objetivo desse trabalho é refletir sobre a articulação entre história, política e educação a fim de salientar a importância da educação no contexto da luta de classes. Trata-se, ainda, de explicitar os sentidos de educação e política para os subalternos na medida em que a luta de classes assume uma dimensão sempre mais ideológica, de modo que se torna sempre mais urgente elaborar uma história materialista da cultura, que implica a crítica a um tempo espacializado e sucessivo, como encadeamento contínuo dos fatos do passado, próprio da história da cultura ocidental e assimilada sem crítica pelo marxismo na vertente da Segunda Internacional.

A concepção de um tempo linear e pontual, constituído de fatos alinhados na relação causa e efeito, tem uma força política e ideológica na manutenção de um projeto de dominação social que se sustenta na apropriação da força de trabalho pelo capital; para Benjamin, uma das principais condições para efetivar transformações radicais seria liberar o materialismo histórico das noções de progresso e 
causalidade, abordando as relações sociais em geral enquanto expressão de um conjunto articulado no qual o passado atinge "um grau de atualidade" na trama do presente:

A superestrutura é a expressão da infraestrutura. As condições econômicas, sob as quais a sociedade existe, encontram na superestrutura a sua expressão - exatamente como o estomago estufado de um homem que dorme, embora possa "condicioná-lo" do ponto de vista causal, encontra no conteúdo do sonho não o seu reflexo, mas a sua expressão. O coletivo expressa primeiramente suas condições de vida. Estas encontram no sonho a sua expressão e no despertar a sua interpretação (BENJAMIN, 2009, K 2,5, p. 437).

Para tanto, faz-se necessário subverter a abordagem da realidade, buscar o detalhe, o insignificante, o abandonado à margem da história e contextualizar as partes em novas configurações para mostrá-los em sua materialidade e força crítica. Neste conceito de história e na proposta de uma história materialista da cultura tem-se também a renovação da política na sua dimensão de luta de classes e, a partir desta subversão de leitura da realidade, tem-se também um novo conceito de educação.

Cabe explicitar aqui que o conceito de educação que buscamos nos escritos de Benjamin referese, em alguns momentos, ao sistema escolar alemão, mas, o que nos interessa mais que tudo, é mostrar que a educação se apresenta em seus escritos como modo de vida construído a partir das formas modernas de relação social e de vivência urbana que geraram, ao longo de um processo de séculos, a formação de uma nova sensibilidade e de um modo de pensar no qual sub-repticiamente se alojou o mito que a modernidade pretendia superar com a afirmação da nova racionalidade científica e tecnológica.

Esta leitura pode ser rastreada em vários escritos de Benjamin, como por exemplo, o ensaio sobre Eduard Fuchs ou ainda em $A$ obra de arte na era de sua reprodutibilidade técnica, ${ }^{2}$ mas aparecem em toda a sua força crítica nas Teses sobre o conceito de História. Conforme Löwy (2005, p. 39), as Teses se apresentam como o documento mais significativo no pensamento revolucionário desde as Teses sobre (ou contra) Feuerbach, de Marx. Um documento no qual "o ponto de vista dos vencidos" abrange, ao lado dos trabalhadores explorados, a história de todos os oprimidos, desde as "mulheres - metade da humanidade - aos judeus, ciganos, índios das Américas, curdos, negros, minorias sexuais”, ou seja, todos os párias e excluídos de todos os tempos. As contradições que permeiam o modo de vida na modernidade, a desigualdade social que se traduz em miséria absoluta, nos agridem e nos mostram com clareza que a ideia de futuro e de progresso que nos propõe esta sociedade é ilusória e mistificadora, o que torna as Teses benjaminianas de gritante atualidade.

\footnotetext{
${ }^{2} \mathrm{O}$ texto se insere no contexto da produção da chamada "Obra das Passagens" (sobre a sociedade moderna a partir do sec. XIX) e dele existem três versões: a primeira escrita em alemão, a segunda em francês (com correções), publicada na revista do Instituto em 1936; a última versão foi escrita entre 1937-1938. Conforme WOLIN (1994, p. 170), A obra de Arte precisa ser entendida no projeto benjaminiano de elaborar uma História materialista da cultura, bem como no confronto com uma estética fascista da violência.
} 
As Teses são o fruto de um longo trabalho de reflexão sobre o arcabouço teórico que forma o pensamento moderno, traduzindo-se no esforço em contribuir para a elaboração de uma história materialista da cultura, de fundo essencialmente político na medida em que explicita as relações de poder que se consolidam e se sustentam no âmbito da ideologia, no modo de pensar e de ser de uma sociedade determinada por relações de dominação que se sedimentam no processo de produção e reprodução de mercadorias. As Teses nos instigam a pensar as contradições do presente com a força negativa da dialética, que se expressa na crítica radical aos marxismos deterministas que se produziram na senda de Marx.

Aliamos ainda a esta leitura alguns fragmentos de Passagens, material de pesquisa que guarda preciosos tesouros para explicitar o projeto benjaminiano de romper com a linearidade histórica própria da narrativa dominante e contrapor ao pensamento burguês a radicalidade da noção de dialética, tentamos explicitar a relação entre história, política e educação.

\section{Uma história materialista da cultura como novo projeto de educação:}

A criança é capaz de fazer algo que o adulto não consegue: rememorar o novo (BENJAMIN, 2009, K 1a, 3, p. 435).

A proposição de uma história materialista da cultura se insere no objetivo de superar a aparência de um saber objetivo e pontual, especializado e espacializado, para abrir a senda de uma dialética negativa, dialética que, em sua força destrutiva, identifica as tensões geradas pelas contradições que permeiam a textura do real e possibilita avançar na dimensão de uma nova temporalidade histórica. Para tanto, trata-se de mudar a nossa visão de mundo e da história para buscar os instantes de ruptura no seu movimento: "para que um fragmento do passado seja tocado pela atualidade não pode haver qualquer continuidade entre eles" (BENJAMIN, 2009, N 7, 7, p. 512). No fundo, "a história se decompõe em imagens", mônadas ou constelações, que o historiador materialista precisa reconhecer baseando seu procedimento na "presença de espírito e na dialética" (BENJAMIN, 2009, N 11, 4, p. 518).

O que perpassa os escritos aqui abordados é que uma história da cultura, seja ela materialista ou idealista, é essencialmente política na medida em que o processo cognitivo, no contexto da sociedade moderna, não é neutro e nem empático, mas sim apropriado no processo produtivo e tornado mecanismo de consolidação das relações de poder, traduzindo-se em novas formas de dominação. Esta questão nunca foi tão atual quanto no momento que vivemos, quando as corporações multinacionais se apropriam do saber produzido para alavancar e ampliar seus mecanismos de acumulação do capital. Nunca como hoje a expressão de Francis Bacon, o conhecimento é poder, encontrou a sua concreticidade e nunca como hoje a maioria da população, incluindo os que frequentam escolas e universidades, se encontram alijados do conhecimento realmente produzido. Este conhecimento nunca 
foi tão concentrado nas mãos de especialistas e apropriado por corporações quanto na contemporaneidade.

Ao buscar os rastros do passado na trama do presente, na diversidade e complexidade do entrecruzar de imagens dialéticas, Benjamin redefine a própria dialética e explicita os limites do marxismo, nas diversas vertentes que este tomou a partir da política do início do século XX. Ao mesmo tempo, revigora a dialética, trazendo à tona a sua força radical de crítica e de transformação da realidade.

A crítica a todas as formas de historicismo vigentes em sua época visa a liberar o materialismo histórico das noções de linearidade e progresso, com o pressuposto da causalidade e do determinismo, que retiram da história as características principais do seu movimento contraditório e imprevisível. "Dizer que o método dialético trata de situações históricas concretas não é o bastante"; é necessário explicitar as significações do presente a partir da "intromissão do passado", que se redefine ao atingir "um grau de atualidade" mais alto até que em seu próprio tempo (BENJAMIN, GS. V-I, p. 494-495).

Benjamin (2009, N 11 a, 1, p. 518-19) recorda em Passagens, que "no decorrer do século XIX, quando a burguesia consolidou sua posição de poder, o conceito de progresso foi perdendo as funções críticas" que possuía em sua origem. A "opinião de que o progresso se realiza automaticamente fortaleceu-se a partir da teoria da seleção natural, que "favoreceu a extensão do conceito de progresso a todos os domínios da atividade humana”. A questão toma novas dimensões quando se recorda que a força destrutiva da dialética não foi compreendida ou foi esquecida pelos componentes da socialdemocracia alemã que, por isso, ficaram impossibilitados de compreender o "lado destrutivo do desenvolvimento técnico", ou seja, de entender que a técnica inserida no modo de produção capitalista ampliava as condições de exploração do trabalho e de acumulação do capital. A socialdemocracia de fim de século, presa aos limites do positivismo, não se deu conta das "energias destruidoras da técnica" (BENJAMIN, 1985, G II-2, p. 475).

A força destrutiva da dialética se traduz em crítica ao instituído a fim de descortinar novos caminhos de luta e também de sociabilidade. O que existe precisa ser convertido em ruínas, "não por causa das ruínas, mas por causa do caminho que passa através delas” (BENJAMIN, 1987, p. 237). Essa negatividade permite identificar as contradições que se ocultam no discurso positivo, formal, dualista, e possibilita uma nova compreensão da realidade, novas construções e projetos sociais. Identificar a positividade e não a negatividade apresenta-se como o pressuposto para a ilusão de continuidade, base de políticas reformistas. A “concepção determinista alinha-se com um evidente otimismo". A intervenção política pressupõe confiança, mas como um "otimismo na capacidade de ação da classe e não nas circunstâncias nas quais a classe atua". (BENJAMIN, 1985, G II-2, p. 488). Fazer a crítica ao determinismo e ao modo como a noção de progresso se alinhava com uma visão otimista da história era urgente para tirar a classe trabalhadora da ilusão de seguir a marcha dos tempos. 
O conceito de progresso precisou opor-se à teoria crítica da história a partir do momento em que deixou de ser usado como medida de determinadas transformações históricas para servir como medida da tensão entre um lendário início e um lendário fim da história. Em outras palavras: tão logo o progresso se torna a assinatura do curso da história em sua totalidade, o seu conceito aparece associado a uma hipóstase acrítica e não a um questionamento crítico (BENJAMIN, 2009, N 13, 1, p.520).

No embate com as teorias deterministas e a imagem da linearidade histórica se fazia necessário entender o passado como "uma sobrevivência do compreendido, cujas palpitações são sensíveis até o presente". A “tarefa do materialismo histórico é efetivar esta experiência com a história, que é originária para qualquer presente" (BENJAMIN, GS. II-2, p. 467-469). O passado tem sua materialidade no presente, a partir do momento em que, na articulação entre vivido e lembrado, o passado assume um grau de atualidade. Trata-se, portanto, de redefinir a visão histórica, até então entendida como o encadeamento de pontos fixos considerados "o ocorrido", conferindo-se "ao presente o esforço de se aproximar, tateante, do conhecimento desse ponto fixo"; a nova perspectiva implica inverter essa relação: "o ocorrido torna-se a reviravolta dialética, o irromper da consciência desperta", que também renova o ponto de abordagem, atribuindo-se à "política o primado sobre a história" (BENJAMIN, 2009, K 1, 2, p. 433).

A dimensão política desta nova história está no convite implícito aos oprimidos a redimir, no contexto de agora, o sofrimento e a opressão dos oprimidos do passado. Significa sair do plano da teoria para a ação política, ação destrutiva e transformadora. Uma ação que precisa "prever, por assim dizer, o presente", porque as situações mudam no contínuo movimento da história (N 12a, 1, p. 520). A história materialista da cultura, neste sentido, apresenta-se também como ação revolucionária. Desta perspectiva se entende a política enquanto movimento da luta de classes, relação historicamente produzida entre dominantes e dominados. Emancipar-se do domínio do pensamento burguês, do conformismo que identifica com os vencedores, para firmar-se como consciência crítica e autônoma.

Este significado de política permeia a ideia de educação presente nos escritos benjaminianos: visto que nos socializamos a partir de nossa condição de classe que, como diz o próprio Benjamin (2002) em texto de 1929, é uma condição determinada já no ventre materno e consolidada ao longo da vida, a educação se faz ao longo da vida e implica o reconhecimento de nossa condição de classe. A educação, portanto, se entrelaça com a política no seu sentido de evidência das contradições e está implicada na necessidade de formular uma história materialista da cultura.

Isto fica evidente quando Benjamin fala da importância do teatro infantil na escola, acentuando que, na formação da criança, "não se necessita daqueles milhares de palavrinhas com as quais a burguesia mascara as lutas de classes de sua pedagogia" (BENJAMIN, 2002, p. 118). Uma pedagogia 
comunista não pode ser "não dialética e rompida interiormente" entre bem e mal, sujeito e objeto, como a pedagogia burguesa que hipostasia a infância e a adolescência, assim como "hipostasia uma essência absoluta do ser humano e do cidadão", essências que "são máscaras complementares entre si”, enquanto posições abstratas que permitem esconder a desigualdade social, a exploração do trabalho e os conflitos sociais (BENJAMIN, 2002, p. 121-122).

A dimensão política da educação se encontra no fato que esta "é função da luta de classes, mas não apenas isso. Ela coloca, segundo o credo comunista, a avaliação completa do meio social dado a serviço de metas revolucionárias" (BENJAMIN, 2002, p. 123). Ou seja, a educação dos filhos da classe trabalhadora precisa apresentar-se como um meio de questionamento da filosofia idealista que permeia o projeto burguês para pressupor um trabalho efetivo de construção das bases de uma história materialista da cultura. Para tanto, a classe trabalhadora precisa tomar em suas mãos o processo educativo de seus filhos, uma questão que Marx já acentuava na Crítica ao Programa de Gotha.

Tendo como pressuposto a luta de classes, a construção de uma história materialista da cultura tem como tarefa identificar as afinidades entre tempos que se entrecruzam, ou seja, os rastros daquilo que a história idealista burguesa oculta porque não lhe interessa mostrar. O que se oculta? A vida e os sonhos dos vencidos; os movimentos insurrecionais e as mais variadas formas de resistência cultural e política que sempre existiram ao longo da história da sociedade moderna, mas que, na narrativa histórica, não aparecem porque foram movimentos vencidos, ou porque sua unidade era frágil e facilmente rompida pelas ações das classes dominantes, ou porque foram estigmatizados como movimentos desordeiros, "casos de polícia", de loucura coletiva ou de fanatismo religioso, por questionarem a ordem instituída.

A dialética, desta perspectiva, apresenta uma força destrutiva e mobilizadora, uma "força de ruptura" que arrebata e que "coloca em questão o fechamento dos diferentes domínios do saber e de sua formação" (BENJAMIN, 1985, GS. II-2, p. 467). Deste modo, história, política e educação se unificam e se transformam em força explosiva, que pode eclodir em ação transformadora.

\section{Notas sobre as Teses sobre o Conceito de História - repensando a educação:}

Em cada época, os vivos descobrem-se no meio-dia da história. Espera-se deles que preparem um banquete para o passado. O historiador é o arauto que convida os defuntos à mesa (BENJAMIN, 2009, N 15, 2, p. 523).

Os escritos aqui comentados prenunciam as Teses sobre o Conceito de História, das quais partimos para algumas notas, visto a sua abrangência e complexidade. Primeiro, salientamos a nova abordagem da história: como se acentua na Tese VI, a imagem do passado lampeja no presente, mas, "se não for reconhecida como uma de suas próprias imagens, tende a desaparecer irrecuperavelmente". Reconhecer estas imagens e suas afinidades com o momento vivido significa "apropriar-se de uma 
reminiscência, tal como ela relampeja no momento de um perigo" (BENJAMIN, 1985, p. 224). Ou seja, trata-se de romper com o ciclo linear da história e identificar no presente imagens que nos permitam um outro ponto de vista que mostre a realidade da perspectiva dos vencidos. Assim como o poeta (Baudelaire), que sente despertar a paixão ao reconhecer na multidão o olhar da passante, esta nova abordagem visa reconhecer o conflito, as contradições do social, salientando a perspectiva dos dominados. Trata-se de uma tarefa eminentemente política: a de identificar as possibilidades de transformação a partir dos elementos que o presente nos oferece.

Cabe ao materialismo histórico fixar uma imagem do passado, como ela se apresenta, no momento do perigo, ao sujeito histórico, sem que ele tenha consciência disso. O perigo ameaça tanto a existência da tradição como os que a recebem. Para ambos, o perigo é o mesmo: entregar-se às classes dominantes como seu instrumento (BENJAMIN, 1985, p. 224-5).

Toda imagem do passado não reconhecida no presente se perde; portanto, historiador materialista precisa ficar atento para reconhecer os detalhes, os nuances, as imagens, para reinterpretar a história da perspectiva dos oprimidos, sujeitos históricos que, envolvidos pela ideologia dominante, nem se dão conta da forma como são envolvidos. Trata-se de uma perspectiva histórica eminentemente política e que traz em si a proposta de uma nova compreensão da educação enquanto formação para um modo de vida.

O dom de despertar no passado as centelhas da esperança é privilegio exclusivo do historiador convencido de que também os mortos não estarão em segurança se o inimigo vencer. E esse inimigo não tem cessado de vencer (BENJAMIN, 1985, p. 224-5).

A perspectiva política no movimento da luta de classes ressalta nesta Tese, que tem como pano de fundo a crítica ao modo como se produz o conformismo social e como funciona a ideologia no contexto da luta de classes. Entende-se aqui que o sujeito histórico é a classe potencialmente revolucionária, aquela capaz de romper com o conformismo e com a identificação com os vencedores firmando a sua identidade de classe.

Para Löwy (2005, p. 66) liberar a tradição do conformismo significa "restituir à história sua dimensão de subversão da ordem estabelecida, edulcorada, obliterada ou negada pelos historiadores 'oficiais"', reinterpretar o passado retirando-o do limbo de neutralidade no qual ele foi lançado. Esta questão é expressão de um processo formativo e educativo que envolve as classes populares na trama ideológica da história neutra e pontual. A ideia do despertar tem aqui um conteúdo político radical, na necessidade de reconhecer os fios que se tecem na obscuridade do movimento histórico, na urgência em identificar nas lutas históricas seus sinais nas relações sociais que compõe o momento atual, como fracasso, domínio e subordinação mistificados por uma ideia de verdade única e eterna. 
A Tese 11 retoma a temática do conformismo, mostrando que as classes trabalhadoras são iludidas também por seus representantes diretos, os partidos e sindicatos: "nada foi mais corruptor para a classe operária alemã que a opinião de que ela nadava com a corrente", nas ideias de progresso, de trabalho como fonte de toda a riqueza e da neutralidade tecnológica. Nesta Tese Benjamin retoma a crítica de Marx ao Programa de Gotha acentuando que o trabalhador tem como única propriedade a sua força de trabalho e que, na sociedade capitalista, "está condenado a ser 'escravo de outros homens, que se tornaram... proprietários"'. Os socialdemocratas esquecem-se de perguntar como o trabalho se torna riqueza e para quem, abstração que atua no fortalecimento da dominação dos homens e da natureza pelo capitalismo e mais, abrindo as portas ao nascimento do fascismo (BENJAMIN, 1985b, p. 227-228).

Escrever a história da perspectiva materialista significa mostrar como funciona a ideologia e como, em cada momento histórico, a "elite dominante se apropria", por vários meios, da "cultura anterior e a integra a seu sistema de dominação social e ideológico", ou seja, para Benjamin "a história da cultura 'deve ser integrada à história da luta de classes"' (BENJAMIN, GS I, 3, p. 1240). Dizemos: desvelar o que se oculta nas dobras e fissuras do tecido social, para tornar "a própria colasse combatente e oprimida" o "sujeito do conhecimento histórico" (BENJAMIN, 1985b, p. 228). Este é um processo educativo eminentemente político, que tem como objetivo a transformação da sociedade. Educar significa fazer germinar, no solo pantanoso e cheio de armadilhas da sociedade moderna, uma nova forma de entender a realidade a partir de seus conflitos e de suas contradições. Trata-se de um trabalho exaustivo, que exige empenho e dedicação constante, tanto no questionamento da ordem social vigente no âmbito dos movimentos sociais e políticos, quanto na escola, para a qual Benjamin dedica alguns escritos.

\section{Notas sobre a educação escolar:}

A educação da criança exige: deve-se abranger toda a sua vida. A educação proletária exige: deve-se educar em um terreno delimitado (BENJAMIN, 2002, p. 113).

Benjamin se aproxima de Gramsci (1975) na perspectiva de educação acima descrita e também no que tange à educação escolar. Para Gramsci, a educação precisa ser um fogo vivo que liberta. Já no escrito Socialismo e cultura Gramsci acentua a diferença entre uma educação formativa de uma educação que informa apenas, como se o cérebro do estudante fosse um arquivo pronto a armazenar informações em gavetas, a abrir quando aparecesse a necessidade. A educação precisa transformar a vida por meio do conhecimento.

Benjamin, na sua crítica ao sistema escolar alemão lamenta que esta escola tenha substituído a formação, própria da tradição alemã, pela instrução, fragilizando enormemente o processo de 
conhecimento. Em Rua de Mão Única, Benjamin nos diz que o que alimenta a vontade de modo vital é a imagem; com "a mera palavra", a vontade "pode, no máximo inflamar-se, para em seguida continuar a arder chamuscada. [...] Não há representação sem inervação” (BENJAMIN, 1987, p. 40).

Mas a palavra pode ser o elo entre pensamento e imagem, o que se pode deduzir da afirmação de que a "imagem é aquilo em que o ocorrido encontra o agora num lampejo, formando uma constelação" (BENJAMIN, 2009, N 2a, 3, p. 504). Como expressar esta constelação para o leitor comum? Pela escrita: citando um texto de Joubert sobre o estilo, Benjamin mostra que as palavras "inspiram a confiança naquele que se serve delas para tornar seus pensamentos mais inteligíveis". As palavras "mostram que o autor remoeu por muito tempo o pensamento ou o sentimento expresso", mas possuem um conteúdo ideológico de fundo, pois se costuma identificar clareza com verdade (BENJAMIN, 2009, N 15a, 3, p. 523).

O otimismo de Benjamin em relação às novas tecnologias de apresentação da imagem no seu aspecto pedagógico é muito claro. Certo que, na época, ainda não se dispunham das "vantagens tecnológicas" que a pedagogia, hoje, possui. O que se acentuou no processo educativo foi o distanciamento entre formar e instruir. As novas tecnologias de nada servem sem o conteúdo dos clássicos para a formação das novas gerações.

Cabe explicitar os pressupostos que fundamentam a estrutura curricular das escolas, os seus objetivos implícitos, ocultos por uma prática de apresentação do conhecimento como algo neutro, pontual, inserido em uma história contínua e progressiva, com uma ideia de verdade absoluta. Da perspectiva política, este tipo de abordagem, com sua carga ideológica, tem o objetivo de adaptar as crianças à ordem social instituída, tornando-os pacíficos e conformados. A este tipo de formação vincula-se a empatia com resultados desastrosos sobre as classes trabalhadoras. Para Benjamin estes limites precisam ser superados e isso só pode acontecer se a classe operária tomar nas suas mãos o processo de sua formação.

Um projeto de educação proletária precisaria ter como princípios fundamentais superar as hipostasias próprias da formação burguesa, presentes na educação escolar como conceitos abstratos e parciais, inquestionáveis porque apresentados como verdade única; universalizar a formação politécnica, voltada para a formação integral da criança e do adolescente; propor uma formação multidisciplinar voltada a articular história, política e arte, mostrando que a cultura pode ser lida de mais de um ponto de vista; diferenciar a educação das crianças da dos adultos, entendendo que a criança tem características especiais enquanto sensibilidade ainda não domesticada e, finalmente, pautar a educação pela dialética materialista, entrecruzando teoria e prática ou fazendo da teoria o elo transformador da prática. 


\section{Conclusão:}

O que nos propusemos neste artigo, composto de breves notas em relação à profundidade dos escritos aqui citados, foi levantar alguns pontos que pudessem esclarecer aspectos da relação entre história, política e educação a partir do que poderia se constituir na formulação de uma história materialista da cultura. A partir da escrita sofisticada de Benjamin, trazendo algumas de suas densas metáforas, tentamos mostrar a força crítica de seus escritos, ao mesmo tempo em que tentamos encontrar uma ideia geral de educação, que perpassa a história da modernidade. A crítica a uma historicidade linear e progressiva, as interrogações sobre uma história quantitativa e pontual, a crítica ao universal pretensamente verdadeiro para mostrar o efêmero, o passageiro, o particular fragmentado, suprimido pela história dos vencedores, tudo isso nos remete a uma ideia inovadora de educação vinculada à luta de classes.

Expressão de uma época, o pensamento de Benjamin continua a nos instigar na medida em que, mostrando as feridas de seu tempo e as condições reais de barbárie que caracterizavam o seu momento histórico, interroga a nossa época e nos incita a buscar saídas para a superação dos problemas que enfrentamos.

\section{Referências}

AGAMBEN, Giorgio. Infância e História - Destruição da experiência e origem da bistória. Belo Horizonte, UFMG, 2005.

ARENDT, Hannah. Homens em tempos sombrios. São Paulo: Companhia das Letras, 1987.

BENJAMIN, Walter. Paris, die Hauptstadt des XIX Jahrhunderts. In: Illuminationen. Frankfurt a.M.: Suhrkamp Verlag, 1977, p. 170-184. (Ill.). 
Essays, Vortraege.) Frankfurt a.M.: Suhrkamp Verlag, 1985.

. Obras Escolbidas - Magia e técnica, arte e política. São Paulo: Brasiliense, 1985b.

Sociologia. São Paulo: Ática, 1985c.

. Obras Escolbidas II - Rua de Mão Única. São Paulo: Brasiliense, 1987.

. Gesammelte Schriften. V-1 e V-2, (Das Passagen-Werk). Frankfurt

a.M.: Suhrkamp Verlag, 1991.

. Gesammelte Schriften I-1,2,3, Frankfurt a.M.: Suhrkamp Verlag, 1997.

Reflexões sobre a criança, o brinquedo e a educação. São Paulo: Duas Cidades/Editora 34, 2002.

Walter. Passagens. Belo Horizonte: Ed. UFMG, 2009.

CAPISTRANO, Tadeu (Org.). Benjamin e a obra de arte: técnica, imagem, percepção. Rio de Janeiro: Contraponto, 2012.

CHAVES, Ernani. É possível uma história materialista da cultura? Benjamin (re) lê Friedrich Engels. In: No limiar do moderno - Estudos sobre Friedrich Nietzssche e Walter Benjamim. Belém: Paka Tatu, 2003.

GRAMSCI, Antonio. Scritti Giovanili (191401918). Torino: Einaudi, 1975.

JAMESON, Fredric. Marxismo e forma. Teorias dialéticas da literatura no século XX. São Pulo: Hucitec, 1985.

LOWY, Michael. Walter Benjamin: aviso de incêndio. São Paulo: Boitempo, 2005.

SCHLESENER, Anita Helena. Os tempos da História. Brasília: Liber Livro, 2011.

Benjamin leitor de Marx: na senda de Das Passagen Werk, publicado na Revista Crítica Marxista, n. 36, 2013, p. 27-41.

SELIGMANN-SILVA, M. (Org.) Leituras de Walter Benjamin. São Paulo: Annablume, 2007, p. 51-64.

WOLIN, Richard. Walter Benjamin an Aesthetic of Redemption. Un. California Press, 1994. 
Recebido em: 10 de maio de 2018. Aprovado em: 12 de junho de 2018. 